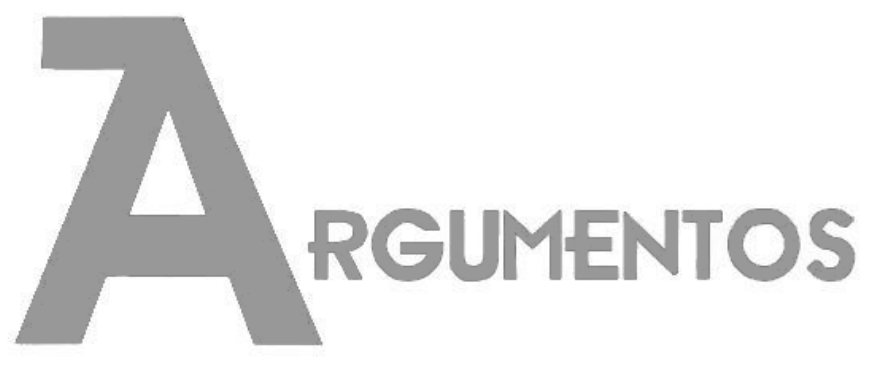

Vol. 18, n. 2, jul./dez. 2021 ISSN: 2527-2551 (online)

https://www.periodicos.unimontes.br/index.php/argumentos

\title{
Hinchas organizados: ¿barras bravas o barristas sociales? Una mirada desde Colombia y Ecuador
}

Jacques Ramírez G. ${ }^{1}$

Santiago Salazar ${ }^{2}$

Recebido em: 29/07/2021

Aprovado em: 10/08/2021

\begin{abstract}
Resumen: Si bien muchos de los hinchas de fútbol han sido categorizados en la región como 'barras bravas', sobre todo por la permanente estigmatización como sujetos violentos movidos por la pasión, el artículo se sumerge en el análisis del denominado 'barrismo social'. Por este término se entiende aquellas actividades y acciones que realizan los hinchas organizados que sobrepasan el campo deportivo y se introducen en temas de apoyo, lucha y ayuda en los ámbitos sociales (barrial, comunitario, societal) o político. A partir del análisis con hinchas de Colombia y Ecuador el estudio da cuenta de nuevas sociabilidades públicas urbanas (más consolidadas en el primer país) que ha permitido una auto reflexión de su tejido organizacional e identitario que permite ver a las hinchadas no solo como sujetos políticos, sino como nacientes movimientos sociales.
\end{abstract}

Palabras clave: Hinchas, organización social, identidad; Colombia; Ecuador.

\section{Torcidas organizadas: Barras bravas ou bairristas sociais? Um olhar da Colômbia e do Equador}

Resumo: Embora muitos adeptos de futebol na região tenham sido classificados como 'barras bravas', principalmente devido à permanente estigmatização dos mesmos como sujeitos violentos movidos pela paixão, este artigo analisa o chamado 'barrismo social'. Por este termo entendemos as actividades, lutas e acções levadas a cabo por apoiantes organizados que vão para além do campo desportivo e são introduzidas em questões de apoio e ajuda nas esferas social (vizinhança, comunidade, sociedade) ou política. Com base na análise com torcidas da Colômbia e do Equador, o estudo fornece um relato de novas sociabilidades públicas urbanas (mais consolidadas no antigo país) que permitiu uma auto-reflexão do seu tecido organizacional

\footnotetext{
1 Doctor en Antropología Social. Universidad de Cuenca, Ecuador. E-mail: jacques.ramirez@ucuenca.edu.ec. ORCID: https://orcid.org/0000-0001-6334-2874.

2 Maestro en Sociología Política. Flacso-Ecuador. E-mail: santiagosalazar9512@gmail.com. ORCID: https://orcid.org/0000-0002-4941-8489.
} 
Dossiê | Hinchas organizados: ¿barras bravas o barristas sociales? Una mirada desde Colombia y Ecuador (RAMÍREZ, Jacques; SALAZAR, Santiago)

e identitário, o que permite as torcidas serem vistos não só como sujeitos políticos, mas também como movimentos sociais nascentes.

Palavras-chave: Torcidas; organização social; identidade; Colômbia; Equador.

\section{Organized fans: Barras bravas or social supporters? A view from Colombia and Ecuador}

Abstract: Although many soccer fans have been categorized in the region as 'barras bravas', mainly due to the permanent stigmatization as violent subjects driven by passion, this article dives into the analysis of the so-called 'barrismo social'. This term is understood as those activities, figths, and actions carried out by organized fans that go beyond the sports field and are introduced into issues of support and help in the social (neighborhood, community, societal) or political spheres. Based on the analysis with fans from Colombia and Ecuador, the study shows new urban public sociabilities (more consolidated in the first country) that have allowed a self-reflection of their organizational and identity fabric that allows us to see the fans not only as political subjects, but also as nascent social movements.

Keywords: Fans; social organization; identity; Colombia; Ecuador.

\section{Introducción}

Una de las lecturas dominantes al momento de hablar sobres los hinchas de los equipos de fútbol es la estigmatización como 'sujetos violentos'. En efecto, desde miradas planas, sobre todo de varias autoridades, periodistas, dirigentes deportivos e incluso académicos, se ha visto la violencia como derivada de una irracionalidad colectiva y actos premeditados de grupos juveniles.

Este tipo de argumentaciones han tendido a caracterizar a los hinchas con metáforas biologicistas "son cuerpos extraños que deben ser extraídos del cuerpo social" (Santos, 2003), categorizados como sujetos animalizados "bestias, salvajes" (Alabarces, 2000) o como jóvenes "desordenados y peligrosos" (Magazine, 2008). De igual manera, desde el periodismo deportivo se ha visto a este grupo descontextualizado de la realidad social, económica y política en la que se insertan.

Armstrong (1998) hace también una crítica para el contexto inglés respecto a los estudios sobre los hooligans, señalando que en la década de los ochenta del siglo pasado los medios de comunicación, académicos y el propio gobierno definieron a este grupo como un "problema social". A ellos culparon del aumento de sentimientos de inseguridad - muchas veces basados en suposiciones preconcebidas más que en investigaciones rigorosas - para no poner la mira en el incremento del desempleo y el desmantelamiento del Estado de bienestar en el thatcherismo. 
Dossiê | Hinchas organizados: ¿barras bravas o barristas sociales? Una mirada desde Colombia y Ecuador (RAMÍREZ, Jacques; SALAZAR, Santiago)

Aunque no se puede negar la presencia de alguna forma de violencia en las hinchadas, las cuales han sido categorizados en la región como 'barras bravas', desde la socioantropología del deporte, se han dado algunas explicaciones a este comportamiento. Para Dunning (1995) uno de los factores explicativos de la conducta violenta de los hinchas de fútbol está relacionada de una manera central con normas de masculinidad. Otros autores han planteado que la violencia en los graderíos puede ser entendida como una "agresión ritualizada" en la medida que los actos violentos señalan una disputa por una identidad, un imaginario, un territorio simbólico y a veces real (Alabarces, 2000); una representación de los jóvenes de una agresividad masculina en un contexto de exclusión económica resultante del modelo neoliberal (Magazine, 2008); un espacio de producción y representación de una 'lógica simbólica de masculinidad violenta' (Ramírez, 2010) o producto de la pasión colectiva que se vive en los graderíos dado que el fútbol parece estar diseñado para expresar sentimientos extremos y emociones 'ilógicas' como la pasión (Bromberger, 1994).

Algunas miradas hablan incluso de un proceso de neotribalización o "tribus urbanas", las mismas que "se rigen por la afectividad entre los pares, se ligan a un tótem común, que en el caso de los hinchas organizados son sus tiempos y sus propias barras vistas como entidades autónomas (Santos, 2003).

El objetivo de este artículo es repensar a los hinchas desde otros lentes por fuera del lugar común en el que se les ha analizado y etiquetado, esto es desde el denominado 'barrismo social'. Este término, aún en construcción, hace alusión a la extensión de la identidad clubísitica por fuera del campo deportivo para usar su propio tejido organizativo en nuevas acciones, luchas y formas de sociabiliad pública urbana que aportan a un colectivo mayor ya sea barrial, comunitario o societal. Incluso se puede dar casos de la unión de barras (adversarias en la arena deportiva pero identificados como hinchas) que se juntan para una causa común que tiene fines sociales.

Vale señalar nuestra mirada crítica aquellos estudios en Colombia y Ecuador que ponen de entrada el adjetivo calificativo de 'bravas' a las barras, influenciados más por el lenguaje dominante de los medios de comunicación o heredados de lecturas de otros contextos sobre todo conosureños, que en un conocimiento profundo sobre más dinámicas internas de estos grupos. Algunos de estos estudios, que enfatizan más en el 
Dossiê | Hinchas organizados: ¿barras bravas o barristas sociales? Una mirada desde Colombia y Ecuador (RAMÍREZ, Jacques; SALAZAR, Santiago)

análisis iconológico, de mensajes o semiótico, ${ }^{3}$ se refieren a estos grupos como 'mafias', 'pandillas', 'salvajes', 'vándalos' o 'incivilizados' que "se encuentran al margen de estar constituidos como referentes políticos o sociales-ideológicos" (Salvador y Piñeiro, 2016).

Por otro lado, tampoco queremos caer en lecturas moralistas y/o simplistas donde se ve a las barras (bravas) como un problema y al barrismo (social) como una solución. Por el contrario, lo que abogamos es por un análisis de los hinchadas que salga de los lugares comunes a través de estudios a profundidad o descripciones densas como las que ha realizado Magazine (2008) en su estudio de una barra en México o Clavijo en Bogotá (2004).

Este artículo, constituye un texto exploratorio y preliminar al barrismo social a partir de algunos datos sobre el tema que hemos detectado en estudios preliminares (Salazar, 2021 y Ramírez, 2017). De esta manera el presente trabajo constituye una ventana a una investigación de más largo alcance que pone la lupa a este tema en el contexto de la violencia (?) y las respuestas estatales. Para el caso ecuatoriano nos adentramos en las barras de LDU (Muerte Blanca), Aucas (Armagedón) y El Nacional (Marea Roja). Para el caso colombiano sobre todo las barras involucradas en el proceso consolidado de 'Barras colombianas por la convivencia' y la de Deportivo Pasto (La Banda Tricolor). A nivel metodológico se privilegió una entrada cualitativa, donde se realizaron entrevistas virtuales con miembros de las barras como alternativa metodológica en contextos de pandemia y de estallido social en 2021 (en el caso colombiano), trabajo de campo en los estadios y otros espacios de socialidad (en el caso ecuatoriano) en el 2019 en inicios del 2020, a lo que se suma un análisis de fuentes secundarias tanto en prensa escrita como en los portales virtuales de dichas barras.

\section{Aproximaciones al barrismo social}

El legado del estigma proveniente de los hooligans en Europa y las barras bravas en Latinoamérica, dejó una huella difícil de superar. Las manifestaciones violentas dentro y fuera de los escenarios futbolísticos vinculaban estrechamente a estos grupos

\footnotetext{
${ }^{3}$ Al respecto para el caso ecuatoriano ver: Chela (2019), Ramírez, R. (2018), Monetenegro y Vela (2013), Aguiñaga (2018). Para el caso colombiano ver: Cañón y García (2006), Castaño, Uribe y Restrepo (2104), Castro, Gómez y Jaramillo (2018). Vale señalar que la mayoría los trabajos en esta temática, sobre todo en Ecuador, constituyen tesis de grado, principalmente de la carrera de Comunicación Social.
} 
Dossiê | Hinchas organizados: ¿barras bravas o barristas sociales? Una mirada desde Colombia y Ecuador (RAMíREZ, Jacques; SALAZAR, Santiago)

como los artífices de comportamientos 'irracionales' o hechos vandálicos difundidos rápidamente por un segmento de la prensa.

En efecto, el barra "brava", ese que suelen presentar los medios, es quizás el más pronunciado y reconocido de manera general. Sin embargo, en nuestro trabajo de campo, varios entrevistados supieron señalar que "no toda barra es brava y no todos los bravos son barristas". Aunque suene a frase coloquial, el significado de su potencia radica en comprender que sus esferas de sociabilidad pública urbana (Magazine, 2008) como hinchas van más allá de las graderías, cánticos, viajes, el "calor del tropel" y el aliento en los partidos de fútbol.

Por sociabilidad pública urbana se entiende las maneras específicas en las que la gente actúa a través de las relaciones sociales y se relaciona socialmente a través de acciones. Sa lucha está limitada generalmente a las áreas urbanas, y es "pública” en el sentido de que no tiene que ver directamente con la vida en el hogar o con la familia (Magazine, 2008). De esta manera el hincha, se interesa y se vincula cada vez más en otros procesos sociales y políticos lo que ha dado paso a la denominación de barrismo social.

La propuesta de Fernando Bolaños (2007), al hablar de 'barras populares' contempla una pedagogía que entrelaza el componente teórico sobre el tema y la acción colectiva de los jóvenes en las calles, a partir de la convivencia, el crecimiento del sentir y el vivir en comunidades grupales. Siguiendo a Maffesoli, Bolaños (2007) se explica la existencia de dos componentes claves: la empatía colectiva y la pluralidad de papeles. En conjunto, las dos conllevan a un ejercicio cotidiano de conciencia que parte de un ego para alinearse a la sensibilización y la búsqueda de alternativas y salidas en colectivo, y se asumen así roles sociales en diferentes perspectivas y formas de relacionarse que son orgánicas por: afectos, emoción, empatía, sentimientos de grupismo, vida solidaria, colectividad incondicional, apoyo mutuo y la valoración de otros/nuevos significados que comienzan con sus primeras puntadas en la alineación contra el poder, contra la dominación y la resistencia.

El autor también recuerdan que primero debería entenderse a la barra desde sus componentes internos, con cada integrante, desde sus aspiraciones, necesidades, virtudes y defectos. Este ejercicio introspectivo recoge una suerte de conciencia de la 
Dossiê | Hinchas organizados: ¿barras bravas o barristas sociales? Una mirada desde Colombia y Ecuador (RAMíREZ, Jacques; SALAZAR, Santiago)

comprensión que permita acoger la alteridad del fenómeno, "del bravo", para transformarlo (Bolaños, 2007, págs. 10-11).

\section{Rastreando el significado desde una mirada crítica}

Si bien no existe una definición concreta para "barrismo social", algunos autores se han aproximado para dar ciertas luces y comprender mejor esta noción y propuesta. Villanueva (2014) plantea que la génesis o instauración de este concepto constituye una amalgama compleja de análisis sociológicos, antropológicos, filosóficos, pedagógicos (y políticos añadiríamos) los cuales deben ser discutidos y pensados en su conjunto con el objetivo de sustentar este fenómeno desde distintos campos.

Algunas perspectivas como las de Arroyo (2014) o Londoño y Pinilla (2009) adjudican el nacimiento del barrismo social a la congregación del colectivo barrista colombiano y las reuniones entre diferentes cúpulas (líderes) en busca de potenciar y rescatar lo heterogéneo y positivo de cada barra organizada al interior del país. Es una alternativa propuesta desde el ámbito popular y se fundamenta en valores y sentimientos que resignifican y amplían la realidad del hincha. Por un lado, "los sumerge en su pasión por el mundo del fútbol y, a la vez, mediante la construcción de redes que impliquen la articulación y esfuerzos, voluntades, experiencias y conocimientos, asumen una identidad como sujetos sociales y políticos" (Londoño \& Pinilla, 2009, pág. 75). Aquí vale señalar que en estricto sentido, las barras de fútbol (sin adjetivos calificativos) son organizaciones sociales con un fuerte sentido político incluso en algunos casos con nexos con actores, dirigentes y partidos políticos y en otros con una posición antisistémica pero no a-política. ${ }^{4}$

En efecto, es en Colombia donde más se ha desarrollado esta noción, tanto desde la reflexión académica, la política pública, el activismo, como desde los propios sujetos -hinchas- que de esta manera se han empezado a repensar a sí mismos. Sin embargo, hay que resaltar que los autores citados e incluso los propios hinchas, como veremos más adelante, cuando hablan de "rescatar lo positivo" de las barras dan cuenta del

\footnotetext{
${ }^{4}$ La recurrencia a la imagen del Che Guevara en varias hinchadas es un ejemplo de lo señalado. En él proyectan una visión propia de la barra, del mundo y de ellos mismos como jóvenes, rebeldes, luchadores, revolucionarios.
} 
Dossiê | Hinchas organizados: ¿barras bravas o barristas sociales? Una mirada desde Colombia y Ecuador (RAMÍREZ, Jacques; SALAZAR, Santiago)

estigma social que pesa sobre ellos como 'sujetos violentos'. Por eso observamos que muchas de estas primeras definiciones caen en el ámbito de lo normativo que incluso ha sido apropiada por el discurso oficial.

Así, según Érika Linares (2019) desde la óptica del barrismo social, se parte de la premisa de que los hinchas pueden resolver sus conflictos por otras vías que no sean violentas. "Son más que la parte negativa [...] que le apostaron a su potencial creativo, organizativo y de acción en propuestas que le aportaran al colectivo y a sus propias vidas, propiciando la creación de mejores condiciones y oportunidades" (Linares, 2019, pág. 24). Como se observa, estas lecturas no solo dan a entender de manera simple que las barras bravas son 'lo malo' y el barrismo social 'lo bueno', sino que desconocen los significados, sentidos de pertenencia e identidad que puede generar ser parte de una barra (así sea brava) en la propia vida de los hinchas.

Esta óptica de ver al barrismo social como la solución ha sido incorporada por los hacedores de política púbica en dicho país andino, en donde, en el 2014, se lanzó el "Plan Decenal de Seguridad Comodidad y Convivencia en el Fútbol", y que constituye un caso que involucra en la política pública directamente a las barras (al menos en papel). Aunque desde el título se observa el enfoque securitista, en dicho Plan se define al barrismo social como:

Las acciones encaminadas a redimensionar las formas de expresión y las prácticas de los integrantes de las barras de fútbol que inciden negativamente en los ámbitos individual, comunitario y colectivo, y de potenciar los aspectos positivos que de la esencia del barrismo deben rescatarse. Esta propuesta se fundamenta en procesos formativos tales como el diálogo de saberes, que recogen valores sociales, normas, creencias, ideales y sentimientos, y le permiten a los barristas resignificar la realidad que los sumerge en su pasión por el mundo del fútbol, y asumir así su identidad como sujetos sociales y participativos (Ministerio del Interior, 2014- 2024, págs. 7- 8).

El Plan Decenal manifiesta cómo el barrismo social se fortalece también mediante los estatutos y pactos que emanan como un ejercicio organizativo y, que, según Diana Salazar (2019), tiene sus pilares en los aspectos educativo, cultural, económico, participativo, social, deportivo/recreativo y ambiental (Salazar, D., 2019, pág.169). Este Plan articula varias de las actividades, y además brinda cierta autonomía a aquellas ciudades en donde existe la presencia de barras organizadas. Se entiende 
Dossiê | Hinchas organizados: ¿barras bravas o barristas sociales? Una mirada desde Colombia y Ecuador (RAMíREZ, Jacques; SALAZAR, Santiago)

entonces, la existencia de un trabajo mancomunado que se legitima desde el eje institucional/normativo y trabaja con las/los actores considerándolos como sujetos de la acción social.

En síntesis, vemos que estos intentos de conceptualización o resignificación de las barras desde Colombia parten justamente de esa mirada esencialista de los hinchas como sujetos violentos. Por eso en muchas de estas primeras reflexiones aún aparece esta idea de "superar la parte negativa", "superar la pasión". No está demás señalar que en el caso de Colombia existen una violencia estructural, muchas veces impulsada desde el propio Estado, que ha buscado desde finales del siglo pasado hasta nuestros días controlar el espacio público, incluido el espacio público deportivo, sobre todo a raíz del vínculo entre carteles del narcotráfico que usaban las barras para el microtráfico y que financiaban a ciertos clubes (Quitián 2008). La violencia en los graderíos no puede ser descontextualizada de la realidad social, política y económica en la que los sujetos están insertos.

Estos esfuerzos teóricos aún requieren de un mayor engranaje ya que si bien se busca entender a las barras también como procesos organizacionales de corte sociopolítico por fuera del ámbito deportivo, no terminan de desaparecer los lugares comunes que han encasillado a estos grupos. Lo interesante, como veremos a continuación, es ver como los hinchas van apropiándose de estas nociones, criticando la mirada oficial y solidificando sus propias estructuras, en medio de recientes movilizaciones sociales.

\section{El barrismo social en Colombia}

Siguiendo a Juan Manuel Restrepo (2018), Perú y Argentina lideran en números absolutos las víctimas fatales en el fútbol suramericano con 333 casos para el primero (entre 1964 y 2017) y 323 casos para el segundo (entre 1922 y 2018). De ahí siguen Brasil con 304 casos (entre 1988 y 2017) y, en cuarto lugar, Colombia con 116 casos (entre 2000 y 2018).

Sin embargo, si se analiza en términos relativos, es decir en relación al promedio de muertos por año, Colombia ocuparía el segundo puesto con 6.44 víctimas por año. Esto dio paso a que desde el inicio del nuevo siglo se piense en un marco normativo para 
Dossiê | Hinchas organizados: ¿barras bravas o barristas sociales? Una mirada desde Colombia y Ecuador (RAMÍREZ, Jacques; SALAZAR, Santiago)

regular la presencia de hinchas y normar la seguridad en eventos deportivos. Dos proyectos de ley se enviaron al senado (el Proyecto de Ley número 50 de 2003 y el Proyecto de Ley número 35 de 2004) que no llegaron a aprobarse. No fue sino hasta finales de la déada que se empiezan a aprobar un conjunto de normas que tratan sobre los hinchas con un enfoque securitario: la Ley 1270 de 2009, la Ley 1356 de Seguridad en eventos deportivos (2009), Ley de Seguridad Ciudadana de 2011, Ley 1445 de 2011, el Código de Infancia y Adolescencia, el Sistema de Responsabilidad Penal para Adolescentes, el Código Penal y de Procedimiento Penal y el Código de Policía.

De todas ellas la más importantes en la materia en relación a nuestro tema es la Ley 1270 por la cual se crea la Comisión Nacional para la Seguridad, Comodidad y Convivencia en el Fútbol (CNSCCF), que encabeza del Ministerio del Interior y de Justicia con la asesoría y asistencia técnica del Instituto Colombiano del Deporte (Coldeportes), como organismo asesor del Gobierno Nacional en la implementación de políticas, planes y programas, al igual que la ejecución de estrategias, con la finalidad de mantener la seguridad, comodidad y convivencia en la organización y práctica del espectáculo del fútbol.

Conformada la Comisión Nacional, el siguiente objetivo fue la construcción de Comisiones Locales para la Seguridad, Comodidad y Convivencia en el Fútbol (CLSCCF) en cada municipio o distrito, bajo el mando de las alcaldías. La ley estipuló dentro de sus funciones, en el artículo tercero: "el diseño de un sistema de registro, que permita a los clubes de fútbol tener información actualizada de los miembros de sus barras y concluyendo en un proceso de carnetización". Posteriormente, se pensó en diseñar un modelo organizativo con principios democráticos para las barras, acorde con los artículos 38 y 103 de la Constitución Política (ambos referentes a la libre asociación y democratización de las organizaciones).

Si bien el marco normativo enfocaba en el tema del control de la violencia en los graderíos, muchas barras organizadas sobrepasan sus actividades netamente "clubísticas" de alentar los noventa minutos de juego, y amplían su agenda para empezar a comprenderse como sujetos que se involucran en ciertas actividades sociales, colectivas y políticas como una nueva plataforma de lucha urbana. Como se explicó, este ejercicio de resignificación y apropiación de nuevos espacios, tuvo un hito histórico (y presuntamente fundacional), que data de julio de 2006 cuando los representantes de 
Dossiê | Hinchas organizados: ¿barras bravas o barristas sociales? Una mirada desde Colombia y Ecuador (RAMÍREZ, Jacques; SALAZAR, Santiago)

19 de las barras de fútbol que existían en ese momento en el país y de 2 organizaciones de barras de fútbol tradicionales decidieron organizarse a nivel nacional, a través de la creación del Colectivo Barrista Colombiano" (Arroyo, 2014, pág. 111).

La misión del colectivo ratifica el compromiso por "promover, liderar y fortalecer espacios de tolerancia y convivencia fundamentados en los pilares del barrismo social" (Colectivo Futbolero Colombiano, 2016). En su visión, proyectada de acuerdo con la temporalidad del Plan Decenal de Seguridad, Comodidad y Convivencia en el fútbol, se pensaban para el año 2024 "ser un modelo organizativo incluyente a nivel nacional e internacional, que represente los intereses de los aficionados al fútbol en Colombia" (Colectivo Futbolero Colombiano, 2016).

En diciembre de 2015, en la ciudad de Buga en Colombia, una de las memorias sobre el congreso de barras colombianas encaminado a la paz en el fútbol, recogió 3 puntos importantes a tratar, sobre los cuales predominaba el interés por "la apertura de fronteras para que regrese el fútbol visitante, capacitación y el buen uso de las redes sociales (Colectivo Futbolero Colombiano, 2016). Sobre los dos primeros puntos se vislumbraró la apertura hacia un proceso organizativo cada vez más consolidado y fuerte.

Estos esfuerzos se replicaron en el trabajo en conjunto de diferentes ciudades como: Bogotá, Cali, Medellín, Pasto, Manizales, Armenia, Pereira, Santa Marta, Ibagué, Tunja, Neiva, Cartagena y Barranquilla, entre otras, incorporando los siguientes temas 'códigos' en sus palabras- dentro de sus agendas: 1) el respeto a la vida; 2) el respeto a la infraestructura oficial de las barras (bombos, esculturas, murales, estadios, que forman parte de la cultura futbolística); 3) el respeto a las ciudades por parte de la hinchada visitante; 4) la comunicación para mediar los problemas entre barras; 5) la seguridad, comodidad y convivencia en los viajes, aludiendo al respeto y garantías para el desplazamiento por los buses y las carreteras; 6) respeto por las familias de los barristas; ${ }^{5}$ 7) el compromiso a un ejercicio de autorregulación de los eventos y 8) la realización de congresos periódicos entre los diferentes integrantes (Colectivo Futbolero Colombiano, 2016). En dicho encuentro, se manifestó el malestar por el abandono estatal: "Con el olvido del gobierno y toda la corrupción actual, deberíamos

\footnotetext{
${ }^{5}$ En jerga de barristas colombianos: "La cucha, la hermana y los hijos, no merecen pagar los trapos rotos, respeto a las familias de los hinchas" (Colectivo Futbolero Colombiano, 2016).
} 
Dossiê | Hinchas organizados: ¿barras bravas o barristas sociales? Una mirada desde Colombia y Ecuador (RAMíREZ, Jacques; SALAZAR, Santiago)

valorar lo que nuestra sociedad tiene. A nadie le gusta que destruyan su ciudad" (Colectivo Futbolero Colombiano, 2016).

La incorporación de estos códigos y la promoción del "sí al visitante" rápidamente se difundió en las ciudades del país, desde Pasto a Santa Marta, generando una aceptación masiva. Según se explicó en la "Escuela urbana de Barrismo Popular" (2020), los códigos tienen las bases del colectivo futbolero, pero se reactualizan y varían acorde a los contextos y apropiaciones barristas.

No obstante, el 2017 se constituye como un punto álgido frente al incremento de la violencia y el quiebre de la confianza entre los barristas, dado que, a raíz del asesinato de "Toyota", uno de los líderes del Barón Rojo Sur y clave en la investigación de presuntos hechos de narcotráfico en barras del América de Cali (El País, 2017) y sumado el robo de varios de los trapos de la barra "Rexixtenxia Norte" (Medellín) presuntamente por miembros del "Frente Radical Verdiblanco" (Cali) (Pulzo, 2017), generaron un cambio en las dinámicas del Colectivo Futbolero pasando a autodenominarse como "barras por un mejor país" y posteriormente "Barras Colombianas por la convivencia", nombre vigente hasta la actualidad.

En diciembre de 2018, este nuevo proceso, que ya adjudicaba algunas bases de fondo, toma forma en un encuentro en la ciudad de Medellín con 15 barras populares para concretar "la voluntad de trabajo en pro de un verdadero anhelo de convivencia y en cumplimiento de un camino real en el que se honren los compromisos, los códigos y el trabajo de una manera definitiva" (Barras colombianas por la convivencia, 2019). ${ }^{6}$

Un año después este colectivo vuelve a reencontrarse en la ciudad de Bucaramanga con más barras organizadas, incorporando además una de las mayores muestras musicales conformada por todas las barras. ${ }^{7}$ Este sentido gregario, incorporó un componente político contemplando vías de acción y participaciones para canalizar la disconformidad con las decisiones políticas tomadas por el gobierno colombiano. En ese

\footnotetext{
${ }^{6}$ En la cohesión y el trabajo mancomunado, se unieron: "Holocausto Norte de Once Caldas", "Guardia Albiroja Sur" de Santa Fe, "Frente Rojiblanco Sur" de Junior, "Lobo Sur" de Pereira, "Artillería Verde Sur" de Quindío, "Revolución Vinotinto Sur" de Tolima, "La Hinchada del Ciclón” de Santa Marta, "Fortaleza Leoparda" del Bucaramanga, "Alta Tensión” del Huila, "Aguante Sur" de Patriotas (Boyacá), "Rexixtenxia Norte” del Medellín, "Rebelión Auriverde Norte" del Cartagena, "La Banda del Indio" del Cúcuta, "Los Del Sur de Nacional" y "La Banda Tricolor" del Pasto.

${ }^{7}$ Al respecto ver: https://www.facebook.com/484375178758951/posts/599922067204261/
} 
Dossiê | Hinchas organizados: ¿barras bravas o barristas sociales? Una mirada desde Colombia y Ecuador (RAMÍREZ, Jacques; SALAZAR, Santiago)

sentido, algunas se reunieron para salir a las calles en apoyo al paro del 21 de noviembre del año en mención:

Las 17 agrupaciones que hacen parte de nuestro grupo de trabajo, saldrán a las calles el próximo 21 de noviembre para hacer parte de las protestas desde una posición independiente a la de cualquier partido o corriente política, las diferentes barras del FPC creemos que las intenciones para reformar asuntos laborales, pensionales y de financiamiento de la educación impactan de manera negativa en la clase popular, queremos hacer parte de un ejercicio de presión ciudadana para que el gobierno replantee su manera de conducir el país eso sí, sin acudir a la violencia ni la alteración de la seguridad ni la propiedad de los demás ciudadanos, invitamos a todas las Barras Colombiana por La Convivencia a auto regular la protesta, no permitir personas con capuchas o con intereses ajenos al justo reclamo ciudadano que puedan poner en riesgo la legitimidad de la movilización (Barras colombianas por la convivencia, 2019).

Desde Barras Colombianas por la Convivencia se adoptó la propuesta oficial en torno a luchar contra la violencia, la seguridad, etc., pero interpelan al gobierno a quien piden que "replante su manera de conducir al país" y resignifican y amplían su lucha con demandas populares aponiéndose a las reformas laborales, económicas o educativas propias de los gobiernos de corte neoliberal.

La tercera asamblea oficiada en marzo de 2020, tuvo como epicentro a la ciudad de Manizales, en un contexto emergente de pandemia. Las mesas de trabajo y reuniones en conjunto, suman nuevos pactos, e iniciativas como: mejorar las logísticas para una mejor convivencia en los partidos, apoyo a las barras visitantes como formas de recibir a quienes llegan a la ciudad, las campañas de "sí al visitante" y la congregación de los colectivos murgueros, además de representaciones artísticas y reforzamientos de procesos de base ya establecidos con antelación.

Aunque suene un tanto utópico, la voluntad de la búsqueda de la paz por el fútbol, genera una consigna que todo el grupo comparte en rechazo a las manifestaciones de violencia. Además, el sentido del altruismo también acarrea que ciertas iniciativas o actividades se manifiesten tales como "Gambeta al Covid- 19" propiciada por "La Banda Tricolor" del Deportivo Pasto, y otras similares en términos de recolección de alimentos, recursos y dinero para algunas de las poblaciones afectadas, en las que participaron "Garra Samaria Norte" del Unión Magdalena, "Los Del Sur" de Atlético Nacional y "Lobo Sur" del Deportivo Pereira. 
Dossiê | Hinchas organizados: ¿barras bravas o barristas sociales? Una mirada desde Colombia y Ecuador (RAMÍREZ, Jacques; SALAZAR, Santiago)

Este ejercicio desarrolló también en los y las barristas la emergencia de movilizarse nuevamente por otras causas a raíz del paro colombiano de 2021. En efecto, desde el 28 de abril hasta que terminaron las protestas se congregaron una buena cantidad de barristas, que se articularon desde diferentes escenarios y ciudades. EI estallido social originado en contra de la implementación de la Reforma Tributaria, denominada Ley de solidaridad sostenible, con la cual se daba paso al incremento de impuestos a ciertos productos de primera necesidad de la canasta familiar, sumado a otros malestares, ${ }^{8}$ convocó a multitudinarias manifestaciones sociales que al ser reprimidas violentamente por el Estado provocaron varios heridos, muertos y desaparecidos.

En este contexto, vale resaltar el accionar de algunas barras como "La Banda Tricolor" quienes emitieron un rotundo rechazo a los sucesos violentos propiciados por la policía y el Escuadrón Móvil Antidisturbios (ESMAD). Esta barra instauró y activó una mesa municipal de barrismo en la que participaron varias de las barras organizadas en la ciudad, quienes a su vez se articularon con otros movimientos sociales conformando el Comité de Juventudes de Paro en la ciudad de Pasto, quienes especialmente manifestaron que:

Nos mantenemos en pie de lucha respaldando la movilidad social, que seguiremos en las calles peleando por un país más justo y digno, mostrándole a Colombia que el sur (del país) se cansó de tanto olvido, e invitamos a todos los sectores sociales a que se mantengan en la lucha hasta que no se desmilitarice la ciudad y se garantice nuestro derecho a manifestarnos de manera segura, digna e íntegra (Mesa de barrismo popular y social Pasto, 2021).

De igual manera en Barranquilla, los plantones entre el 12 y 13 de mayo fueron promovidos por la barra "La Banda de los Kuervos" (Atlético Junior), oponiéndose rotundamente a los encuentros disputados por Copa Libertadores entre Junior de Barranquilla y el River Plate de Argentina, y el de América de Cali versus Atlético Mineiro de Brasil. Según el diario El Tiempo, uno de los líderes comunicó: “Consideramos que en

\footnotetext{
${ }^{8}$ Incremento del precio de los servicios básicos, regresividad fiscal, mal manejo de la pandemia, reforma a la salud, reforma de pensiones, reforma a la policía, mejores oportunidades para las/los jóvenes, discriminación sexual, concentración de la riqueza y desigualdad, violencia estructural del sistema.
} 
Dossiê | Hinchas organizados: ¿barras bravas o barristas sociales? Una mirada desde Colombia y Ecuador (RAMÍREZ, Jacques; SALAZAR, Santiago)

este momento no se debe realizar ningún partido de fútbol en la ciudad debido a la crisis político-social que se vive en el país. El fútbol no puede estar por encima de esta problemática" (El Tiempo, 2021). Incluso desde el grupo de barristas hubo declaraciones señalando la disconformidad por realizar la Copa América en Colombia en pleno contexto de paro nacional. Finalmente, la copa no se realizó en dicho país.

Varias barras se sumaron a las movilizaciones y lograron posicionar nuevos acuerdos de convivencia, acción colectiva y de relegar las diferencias para apoyarse y reconocerse. Hinchas de Bogotá, Cali, Pasto, Pereira, Medellín, Villavicencio, Popayán (que inclusive no cuenta con fútbol profesional, pero sí con barras organizadas), Armenia, Bucaramanga y Barranquilla, entre otras, pactaron por la no agresión entre barras y la solidaridad en colectivo, manifestándose juntas en las calles: “Las barras sólo han protagonizado acciones de compartir, como sancochos comunales [...] seguirán implementando la estrategia Goles en paz, un programa integrado por los líderes de las barras de todos los equipos del fútbol colombiano que hacen presencia en la capital del país" (El Tiempo, 2021).

En Cali, el epicentro del paro y de las protestas también las barras circunscribieron acuerdos. El Barón Rojo Sur (América) y el Frente Radical Verdiblanco (Cali) manifestaron que ninguna se mostraba indiferente al estallido, especialmente considerando que la mayoría de sus integrantes son jóvenes que no podían pasar por alto el difícil contexto caleño de esos días. Con la consigna de "hasta que no tengamos paz no habrá fútbol", se reafirma el giro y el quiebre sustancial: las barras ya no solo se mueven por el espectáculo deportivo y por sus equipos. La histórica movilización convocada para el 12 de junio en Bogotá, de la que participaron una gran cantidad de barras por la convivencia, marcó un hito histórico:

Este encuentro representa un hito en el barrismo colombiano y probablemente mundial al lograr juntar a casi la totalidad de las barras populares del país en contra del peor gobierno de la historia de Colombia. El sueño de un mejor país libre de corrupción, desigualdad y violencia no nos lo van a arrebatar y nuestro aporte será siempre el de demostrar que la convivencia es posible en el fútbol y que los barristas somos capaces de cambiar el país desde todo nuestro potencial humano y solidario como actores sociales (Barras colombianas por la convivencia, 2021). 
Dossiê | Hinchas organizados: ¿barras bravas o barristas sociales? Una mirada desde Colombia y Ecuador (RAMÍREZ, Jacques; SALAZAR, Santiago)

Todas estas acciones han dado paso a que los propios hinchas entiendan y definan sus acciones dentro del barrismo social:

Todos tenemos un lema que parte del barrismo social: "el barrismo no es vandalismo", ese es el lema de nosotros Los del Sur [...] Muchos "pelados" fueron rechazados por sus grupos, por la sociedad, por los barrios marginados, donde el Estado nunca les brindó un estudio, una oportunidad de trabajo y que tienen que rebuscársela todos los días para su familia, para el sustento diario, entonces lo que hacemos son actividades, vamos a buscar, vamos a nutrir, vamos a recuperar al "pelado" que está en las drogas, vamos a ayudarle a buscar un trabajo, vamos a ayudarle a estudiar, tocando puertas, todo con el sudor de la frente para que sea útil a la sociedad" (Triviñas, miembro de "Los del Sur", Atlético Nacional, 2021).

Habemos todos los sectores sociales, desde el 'man' que piensa diferente, hasta el man que tiene más, tiene menos, pero todas las clases sociales [...] nosotros somos una cultura social, una cultura urbana y futbolera. La apuesta es esa, que desde La Banda nos apropiemos de todos esos procesos sociales, culturales, porque entendimos que tenemos que crecer como organización, sabemos que como personas y como barristas influimos dentro de esta sociedad [...] tenemos la diversidad de Colombia, de Nariño y de Banda Tricolor, la idea es hacer un barrismo diferente, un aguante diferente (Menor, miembro de "La Banda Tricolor" (Deportivo Pasto, 2021).

Finalmente, todo este trabajo de años, acaba de desembocar en otro encuentro pero de mayor calibre que han denominado como "la primera Asamblea del barrismo colombiano", que incluye a otros sectores y fue realizada en Bucaramanga a mediados de julio del 2021, en donde, al tenor de las movilizaciones que se han desarrollado, fue vista como un espacio de "resistencia, lucha y construcción de un mejor país, convencidos que desde el barrismo popular y social se transformará esta Colombia con verdadera paz".

Siguiendo el contexto emergente del estallido, el logro más importante de esta Asamblea fue la coordinación para la instauración de una consulta popular en acompañamiento con el Consejo Regional Indígena del Cauca (CRIC), una organización fuerte y con bastante relevancia en la coyuntura colombiana. Así lo manifestaron desde La Banda Tricolor: "creo que el tema político es lo más importante, pero obviamente se trabajaron diferentes mesas: arte y cultura, deporte y medio ambiente, derechos humanos, pero en el tema político sí demostramos que estamos bastante fortalecidos después del estallido social" (El Niño Dios, 2021). Como este ejercicio no hemos 
Dossiê | Hinchas organizados: ¿barras bravas o barristas sociales? Una mirada desde Colombia y Ecuador (RAMÍREZ, Jacques; SALAZAR, Santiago)

encontrado otro a nivel regional, y es sin dudas una prueba valiosa de la resignificación de los barristas en Colombia. ${ }^{9}$

\section{Violencia y barrismo social en Ecuador}

En Ecuador el promedio de muertes por año dentro de un escenario deportivo o en enfrentamiento entre hinchas fuera de los graderíos es de apenas 0.38. Cifra absolutamente baja comparada con los 6.44 muertos por año en Colombia o los 6.28 en Perú, por señalar los casos de los países vecinos. En términos absolutos hablamos de 7 fallecidos entre el 2002 y el $2020 .{ }^{10}$

Por su parte Dammert (2007) en su trabajo realizado entre 2004-2007 recuerda que los hechos de violencia eran más entre hinchas y fuerzas policiales que entre miembros de barras organizadas. Como se observa en la tabla adjunta, los casos de fallecidos han ocurrido en las ciudades de Quito y Guayaquil y los actores involucrados son hinchas de Barcelona, Emelec, LDU, Nacional (los cuatro equipos más exitosos del fútbol ecuatoriano) y la fuerza pública.

Tabla 1. Hinchas fallecidos en Ecuador

\begin{tabular}{|c|c|c|c|}
\hline Fecha & Ciudad & Involucrados & Evento \\
\hline 31.05 .2014 & Quito & Hincha de LDU & $\begin{array}{l}\text { Hincha de Liga de } 17 \text { años, } \\
\text { falleció tras una riña callejera. Según un } \\
\text { familiar, el adolescente estaba } \\
\text { 'grafiteando' algo sobre Liga cuando fue } \\
\text { interceptado por un grupo de jóvenes. }\end{array}$ \\
\hline 7.03.2014 & Guayaquil & Hincha de Emelec & $\begin{array}{l}\text { Hincha de Emelec, fue asesinado } \\
\text { por supuestos seguidores de otro equipo } \\
\text { mientras se transportaba en un bus de la } \\
\text { cooperativa Panorama, en Guayaquil. } \\
\text { Recibió impactos de piedra lanzados } \\
\text { desde el exterior, que lo dejaron } \\
\text { inconsciente. }\end{array}$ \\
\hline 4.11 .2012 & Guayaquil & $\begin{array}{l}\text { Hincha de Barcelona } \\
\text { Hincha de Emelec } \\
\text { Policía }\end{array}$ & $\begin{array}{l}\text { Hincha de Barcelona fallece por } \\
\text { el impacto de una bala en la cabeza } \\
\text { mientras se dirigía al estadio }\end{array}$ \\
\hline
\end{tabular}

\footnotetext{
${ }^{9}$ Aunque vale resaltar el caso chileno, en donde -también en el contexto de las movilizaciones de finales del 2019- se obesevó la emergencia de las barras en la protesta social. Al respecto ver: Navarrete y Caro (2020). El caso argentino en torno a las movilizaciones al iniciar el siglo XXI también pueder ser vistas como un antecedente en la región, en donde en la movilización popular aparecieron símbolos como la camista de la selección de fútbol, así como prácticas aprendidas en los estadios como cánticos y tácticas de lucha contra la reprsión (Alabarces, 2006).

10 Un reciente estudio señala que, en este periodo, además del número de muertos, hubo 100 heridos y 82 detenidos (Salazar, 2021).
} 


\begin{tabular}{|c|c|c|c|}
\hline & & & $\begin{array}{l}\text { Monumental para presenciar el clásico } \\
\text { entre su club y Emelec. Supuestos } \\
\text { seguidores del cuadro azul dispararon al } \\
\text { joven a bordo de una camioneta. Otras } \\
\text { imágenes indican que los disparos } \\
\text { pudieron salir de la policía. }\end{array}$ \\
\hline 4.03.2012 & Quito & Hinchas de LDU & $\begin{array}{l}\text { Hincha de LDU que estaba } \\
\text { ubicado en la general sur del estadio Casa } \\
\text { Blanca, falleció al ser empujado por } \\
\text { supuestos compañeros de la barra } \\
\text { Muerte Blanca, cuando su cabeza se } \\
\text { impactó contra el filo de las gradas del } \\
\text { estadio. }\end{array}$ \\
\hline 13.06.2011 & Guayaquil & $\begin{array}{l}\text { Hinchas de Barcelona } \\
\text { Hinchas de LDU }\end{array}$ & $\begin{array}{l}\text { Hincha de Barcelona, falleció en } \\
\text { un centro de salud en Guayaquil, luego } \\
\text { de que fue brutalmente golpeado por } \\
\text { supuestos hinchas de Liga de Quito, tras } \\
\text { el encuentro entre ambos cuadros en el } \\
\text { estadio Monumental. }\end{array}$ \\
\hline 20.06.2009 & Quito & $\begin{array}{l}\text { Hinchas de LDU } \\
\text { Hinchas de Nacional }\end{array}$ & $\begin{array}{l}\text { Hincha de El Nacional, menor de } \\
\text { edad, fue asesinado supuestamente por } \\
\text { hinchas de la barra Muerte Blanca de } \\
\text { LDU, luego de un enfrentamiento entre } \\
\text { ambos elencos en el estadio Casa Blanca. }\end{array}$ \\
\hline 16.09.2007 & Guayaquil & Hinchas de Barcelona & $\begin{array}{l}\text { Un niño murió por el impacto de } \\
\text { una bengala lanzada desde el sector de la } \\
\text { barra Sur Oscura, hacia el sector de } \\
\text { suites, dentro del estadio Monumental, } \\
\text { en el clásico Barcelona vs. Emelec. }\end{array}$ \\
\hline
\end{tabular}

Fuente: Ramírez (2017), Salazar (2021).

Como ya hemos señalado en otros estudios no se puede analizar el caso ecuatoriano sin entender las históricas confrontaciones regionales, sobre todo entre los dos grandes centros de poder: Guayaquil y Quito. A esto hay que sumar los asuntos de las identidades clubísticas, explicados ampliamente desde la socio-antropología del deporte y, la propia estigmatización y rechazo que recae sobre los hinchas organizados, categorizados como 'barras bravas' (Ramírez, 2017). Algo que también es señalado por una ex integrante de una barra:

Es impresionante que existan actos de discriminación y rechazo a los que son expuestos los barristas ecuatorianos, personalmente, cuando he querido ingresar a una tienda después de un partido de futbol los propietarios me han cerrado la puerta o me han negado los productos, a partir de ello, considero que en su gran mayoría los integrantes de la barra han pasado por ese tipo de actitudes por parte del resto de personas (Pinta, 2017). 
Dossiê | Hinchas organizados: ¿barras bravas o barristas sociales? Una mirada desde Colombia y Ecuador (RAMÍREZ, Jacques; SALAZAR, Santiago)

Esta forma de ver a los hinchas dio paso a la elaboración de un marco jurídico y dispositivos de control con un enfoque eminentemente securitista que incluyó la capacitación de la policía londinense a la ecuatoriana. Vale señalar que la mayoría de barras organizadas en el país, surgieron a mediados y finales de los noventa y es parte de lo que denominamos culturas viajeras que se han ido extendiendo desde el cono sur hasta el norte del continente. Las barras 'Sur Oscura' de Barcelona, 'Muerte Blanca' de LDU, 'Mafia Roja' del Nacional o 'Armagedón' del Aucas fueron creadas en esta época y las primeras noticias sobre agresiones y actos violentos aparecen al iniciar el siglo XXI.

Es en el 2007 cuando se dicta la primera "Ley de Cultura Física, Deportes y Recreación" que estipuló la creación de la Comisión Nacional de Control de la Violencia en Escenarios Deportivos la cual tenía entre sus objetivos:

Impulsar las medidas tendientes a evitar la violencia y resolver los problemas por medio del diálogo, la concertación y las acciones coercitivas establecidas en el Código de Procedimiento Penal; desarrollar y ejecutar las medidas de prevención y control de la violencia en eventos deportivos, regulando las obligaciones de los propietarios de las instalaciones deportivas, clubes, dirigentes y deportistas, autoridades deportivas, organizaciones de acontecimientos deportivos y público asistente, así como las funciones de la fuerza pública y demás cuerpos de seguridad relacionados con el control de la violencia en el deporte (Dammert, 2007, pág. 6).

Luego de esto, y conforme sucedía algún evento violento que era hecho noticioso, se dictaminaron otras normas, campañas, ordenzas tales como: el "Reglamento de Calificación, Administración y seguridad de los escenarios para la práctica del fútbol profesional" (2009); las modificaciones a la Ley del Deporte, Educación Física y Recreación que incluyó un nuevo título sobre la violencia en los escenarios deportivos (2010); el Acuerdo Ministerial 078 emitido por el Ministerio de Deportes referente al consumo de bebidas así como a combatir los actos de violencias dentro y fuera de los escenarios deportivos (2012); la campaña "Tarjeta roja a la violencia" (2012); la Ordenanza Municipal 0267 (2012) y la 0556 (2014) de regulación y control de los espectáculos deportivos masivos en la ciudad de Quito; La "Guía de seguridad del hincha del fútbol" (2014) y la campaña "Ecuador es hincha de la Paz" (2014). 
Dossiê | Hinchas organizados: ¿barras bravas o barristas sociales? Una mirada desde Colombia y Ecuador (RAMÍREZ, Jacques; SALAZAR, Santiago)

Pero es en el Código Integral Penal (2014) donde se estipula como una contravención los actos violencia que se originan dentro de los escenarios deportivos sancionando hasta con cien horas de trabajo comunitario y prohibición de ingreso a todo escenario deportivo hasta un año a las personas que: 1 . invadan violentamente y sin autorización el terreno de juego o el escenario. 2. arrojen objetos contundentes a la cancha, al escenario principal, a los graderíos, a los lugares de tránsito o acceso. 3. introduzcan de manera subrepticia a escenarios deportivos o de concurrencia masiva armas blancas, petardos, bengalas o material pirotécnico prohibido.

Como se observa la mayorá de esta normativa coincide con el mismo período cuando se producen los decesos dentro del ámbito futbolístico, y constituye una reacción estatal (tardía) a los casos ocurridos, con una mirada 'pacificadora' y sobredimensionada sobre 'la violencia' en el fútbol ecuatoriano. ${ }^{11}$ Esto dio paso a la implementación del enfoque de seguridad (security) el cual se refiere "a las tareas y medidas dirigidas a prevenir, conjurar e investigar los diferentes tipos de delitos por parte de las autoridades políticas y la burocracia especializada como la policía" (Saín \& Rodríguez, 2014, pág. 323). Posterior a este período se elaboró una normativa más, el Acuerdo Ministerial 8168 (del Ministerio del Interior) llamado “Instructivo de control de ingreso de objetos a escenarios deportivos" (2017), donde se señala:

Los hinchas y aficionados para alentar a sus equipos podrán ingresar a los escenarios deportivos tambores y bombos de membrana transparente; banderas sin astas, pancartas, carteles y demás objetos de similar naturaleza, siempre y cuando no contengan elementos que puedan ser utilizados como armas que puedan generar inseguridad o propicien la violencia en contra de la integridad física de las personas o de sus bienes (Instructivo de control de ingreso de objetos a escenarios deportivos, 2017, págs. 3- 4).

\section{La otra cara de la moneda}

Como ya se indicó en el apartado teórico, una aproximación al barrismo social implica entender aquellas prácticas que los hinchas realizan por fuera de su 'esencial'

\footnotetext{
${ }^{11}$ Vale señalar que según el estudio de Viver (2014) “desde el año 2004 hasta el 2007 la cantidad de personas que invadían los campos deportivos fue disminuyendo sostenidamente hasta llegar a ser solamente 4 en el 2007, es decir el 25\% de lo registrado en el 2004. Esta disminución de infracciones en el 2007 también se evidencia en el cuadro de lanzamiento de objetos al campo de juego".
} 
Dossiê | Hinchas organizados: ¿barras bravas o barristas sociales? Una mirada desde Colombia y Ecuador (RAMÍREZ, Jacques; SALAZAR, Santiago)

papel de alentar, apoyar o hinchar a su equipo. Sin embargo, un elemento que no puede quedar por fuera del análisis tiene que ver con el sentido de identidad colectiva que genera ser hincha. Etnográficamente, la pregunta guía sería: ¿qué pasa con el sentido de pertenencia y organización de los hinchas más allá de su tiempo dedicado al espectáculo deportivo? El trabajo de Pinta (2017) es el primero que nos da una pista (aunque no desarrolla el tema, al analizar a la barra de la 'Sur Oscura':

...Sin embargo, no todo es negativo dentro de las barras bravas, estas se caracterizan en algunos casos por realizar labor social o conocida también como labor comunitaria, este grupo organizado de hinchas, después de las diferentes reuniones acuerdan realizar algún tipo de actividad sin fines de lucro y que beneficien a la comunidad (Pinta, 2017, pág. 14).

Los datos de campo recolectados para el caso ecuatoriano dan cuenta de que el sentido de identidad clubística, pero sobre todo la pertenencia a una barra organizada, sobrepasa los asuntos netamente futbolísticos, y poco a poco se introducen en un barrismo social y popular empezando los hinchas a realizar nuevas iniciativas y actividades grupales, nuevas sociabiliades públicas, que los vinculan más con lo societal/comunitario (sin perder su sentido de identidad como hinchas). A continuación, remarcamos tres casos.

Para arrancar vale señalar que desde el 2018 Ecuador implementó medidas de austeridad en el marco del acuerdo con el Fondo Monetario Internacional (FMI) de febrero de 2019. Estas medidas de corte neoliberal produjeron políticas de ajuste, recortes presupuestarios -sobre todo en el área social-y el consecuente incremento de desempleo y de la pobreza. En efecto, al analizar el nivel de pobreza por ingresos entre 2007 y 2016 se observa que 1,14 millones de ecuatorianos dejaron de ser pobres. Por otra parte, entre 2016 y 2019 casi 541 mil personas caen en esta condición y, finalmente, en 2020 se incorporan 1,33 millones de ecuatorianos a la pobreza. Eso implica que en casi cuatro años (durante el gobierno del ex presidente Lenín Moreno) se habría incorporado a 1,87 millones de personas a la pobreza, una cifra superior a la de personas que salieron de esta condición en diez años (Báez, 2020). A esa situación ya compleja se sumó la crisis política -como las conocidas movilizaciones populares de octubre del 2019-y más tarde la crisis sanitaria consecuencia del SARS-COVID-19, en marzo de 2020. 
Dossiê | Hinchas organizados: ¿barras bravas o barristas sociales? Una mirada desde Colombia y Ecuador (RAMÍREZ, Jacques; SALAZAR, Santiago)

En este contexto, los miembros de la barra del club Aucas (Armagedón) empezaron a socializar en sus redes sociales iniciativas de emprendimientos para ayudar a las personas que se quedaron sin empleo o ayudas para personas que necesitan alimentos:

Son momentos difíciles que el país está pasando, y sabemos que muchos de los Auquistas se encuentran buscando la manera de salir adelante. Es por ello que ayudaremos publicitando sus negocios, emprendimientos. $O$ si necesitan ayuda con alimentos buscaremos la manera de gestionar para que sean ayudados por gente misma del AUCAS o por las entidades del estado. Porque solo el pueblo salva al pueblo organización \#ARMAGEDON (Armagedón, 2020).

Porque el pueblo apoya al pueblo... un emprendimiento auquista!!!: Deliciosa fritada acompañada de mote, papas, maduro y ensalada, todo por 3,50 USD incluida la entrega (Armagedón, 2020).

En la misma dirección los hinchas de LDU, pertenecientes a la 'Muerte Blanca', realizaron igual iniciativa:

En estos momentos de crisis sabemos que muchos negocios están cerrados y otros están atendiendo a puerta cerrada bajo pedido. Nuestra manera de colaborar con los hermanos es ayudarlos a promocionar sus negocios sean mecánicas, servicio de comida a domicilio, tiendas, comida, etc., a través de nuestras redes sociales tratando así de levantar algunos negocios particulares. Si tienen un negocio servicio que ofertar puedes dejar tu afiche o arte con tus datos de contacto y sector donde queda para poder promocionarlo de una mejor manera (Muerte Blanca, 2020).

Vale señalar que la barra de 'Muerte Blanca' viene realizando actividades sociales desde tiempo atrás. Incluso son los únicos que hemos registrado hasta ahora que usan el término de barrismo social, teniendo una página en redes sociales denominada "Muerte Blanca Barrismo Social Ecuador". Por lo general han realizado el conocido "agasajo navideño" o "Blanca Navidad", que es una iniciativa de recaudación de fondos, ropa, juguetes y comida para gente de escasos recursos. Se observa que muchas de las actividades se activan en momentos de crisis o en eventos catastróficos como fue el terremoto del 2016 en donde la barra recaudó y sumó esfuerzos en la ayuda humanitaria a Pedernales, ciudad costera que fue una de las más afectadas por el movimiento telúrico, llevando alimentos no perecederos, ropa, agua y víveres: 
Dossiê | Hinchas organizados: ¿barras bravas o barristas sociales? Una mirada desde Colombia y Ecuador (RAMíREZ, Jacques; SALAZAR, Santiago)

Gracias a todos por el apoyo, llenamos un camión el cual arribó a Pedernales a las 4am. MUERTE BLANCA ECUADOR. BARRISMO SOCIAL" (Muerte Blanca, 2016).

En la incorporación de dichas actividades de carácter social a sus dinámicas deportivas, ellos mismos han resignificado el sentido de ser un hincha. En sus propias palabras:

Un barrista no solo es aquel que deja la vida por sus colores en los estadios si no también quien ayuda a su comunidad a su barrio para sacarlo adelante a través de estos actos queremos dejar claro que un barrista es un hincha no es un delincuente (Muerte Blanca, 2016).

Finalmente, la barra del Club El Nacional, 'Marea Roja' estuvo presente en las movilizaciones sociales de octubre del 2019, cuando el gobierno emitió el Decreto 883, que eliminaba los subsidios a los combustibles, conocido popularmente como 'el paquetazo':

Nuestra identidad es popular, si el gobierno se mete con el pueblo, allí estaremos. Marea Roja como colectivo barrista y social, rechaza las medidas tomadas el pasado día martes en contra de la sociedad ecuatoriana, que traerán consigo el encarecimiento del diario vivir y el retroceso en derechos laborales, sometiendo aún más al pueblo ecuatoriano que día tras día con trabajo duro forja un mejor porvenir, siendo víctimas de una falsa democracia que le ofreció estar con ellos, pero conspira en su contra, a favor de los acaudillados de siempre. Es hora de unirse a la LUCHA, en la calle también tenemos aguante, eso está más que demostrado. OCTUBRE MES COMBATIVO. LA MAREA ROJA A LAS CALLES. (Marea Roja, 2019).

Esta barra también ha sido muy crítica con el mal manejo de la directiva (el equipo descendió a segunda categoría), así como a lo que denominan "lógicas de mercantilización y prohibiciones que emanan de la LigaPro (títeres de Gol TV)". Marea Roja también registra acciones como el festival "Piel, tinta y pasión" que es un servicio de tatuajes, cuyos fondos recaudados van en beneficio de sus integrantes.

Igual que las otras barras, el 2020 en el contexto de la pandemia y en pleno confinamiento, realizaron más actividades en el sentido de barrismo social/popular como el concurso al "mejor tema musical" o las "ollas solidarias" para repartir comida, bajo el lema "solo el pueblo salva al pueblo": 
Proyecto social que venimos realizando para ayudar a las personas más necesitadas. Por favor no te quedes sin comer ni mandes a tus hijos a la cama sin hacerlo. Si necesitas ayuda no dudes en avisarnos, que de lo mucho o poco que tengamos de seguro lo podemos compartir. Si deseas ser parte y colaborar con esta iniciativa escríbenos por interno. iSOMOS MAREA ROJA, la hinchada del pueblo para el pueblo! (Marea Roja, 2020).

¡Las ganas de ayudar a nuestra gente es como la pasión que sentimos por nuestros colores, nunca terminan!! Una vez más salimos a dar una mano a los que más necesitan. (Marea Roja, 2020).

\section{Conclusiones}

El artículo tuvo como objetivo sumergirse en el aún incipiente trabajo investigativo sobre el barrismo social a partir del análisis de hinchas organizados en Colombia y Ecuador. Este ejercicio permitió entender que la estigmatización que adquieren los hinchas vistos como barras "bravas", ha imposibilitado que haya otras lecturas por fuera de esa mirada exclusiva que les cataloga como bárbaros, violentos o salvajes. La primera gran conclusión es que falta mayor investigación de carácter etnográfico para comprender estas nuevas acciones y sociabilidades públicas urbanas, que han sido denominadas como barrismo social o popular.

Los datos de nuestro estudio dan cuenta que estas sociabilidades se activan con más fuerzas en momentos de combulsión social, como han sido las protestas sociales en contra de las políticas neoliberales en Colombia (2021) y Ecuador (2019) (a lo que habría que sumar a Chile) o la llegada de la pandemia en el 2020. La noción de 'lucha' es un término recurrente en el discurso de los barristas que es resignificada en estos contextos de movilizaciones y que está produciendo nuevas relatos identitarios.

Como se vio a lo largo del texto, el caso colombiano es el más visible dado que ya tiene un proceso que aproximadamente 15 años y se ve reflejado en el nivel de organización sólido y maduro al interior de las barras, con diálogos interbarras y de barras con otros movimientos sociales que tienen posiciones políticas similares, sobre todo en contra del gobierno Uribista que el actual presidente representa. Evidentemente, no se puede entender el surgimiento y consolidación de barrismo social colombiano por fuera del contexto de violencia estructural estatal que se ha visto profundizado en los últimos años y la respuesta social manifestada en las recientes 
Dossiê | Hinchas organizados: ¿barras bravas o barristas sociales? Una mirada desde Colombia y Ecuador (RAMÍREZ, Jacques; SALAZAR, Santiago)

movilizaciones de un pueblo cansado de un modelo excluyente. Así como tampoco se puede dejar de poner atención al papel que ha cumplido las relaciones entre las barras con las institucionalidad gubernamental y el marco normativo el cual ha tenido un enfoque securitista en ambos países.

Para el caso ecuatoriano, si bien el comportamiento violento de los hinchas no se refleja en números exorbitantes (sobre todo en comparación con otros países de la región) igual se ha producido una estigmatización de las barras "bravas". No obstante, vemos unos brotes incipientes del barrismo social que tienen un largo tramo por recorrer en comparación con el caso colombiano. Sin embargo no hay duda que en los últimos años se ha producido un potente proceso de autoreflexión orgánica e identitaria del propio sentido de 'ser barrista'.

Por último, a menera de hipótesis, planteamos que las actividades de los hinchas en torno al barrismo social puede empezar a entenderse como un movimiento social que reivindica un sentimiento de identidad clubística, de hinchas pertenecientes a una barra organizada, que se agrupan con fines sociales y políticos y que tienen un fuerte matiz popular. Se requiere más investigación, no solo en los países analizados en este estudio, sino en otros contextos para tener mayores elementos de análisis comparativo.

\section{Bibliografía}

Aguinaga, L. (2018). "Reconocimiento formal en la Ley del Deporte, Educación Física y Recreación de las barras deportivas organizadas". Tesis para la obtención del título de Abogado. Quito: Universidad Central.Álvarez, C. (18 de 05 de 2020). Facebook. Recuperado el 06 de 06 de 2020, de https://www.facebook.com/camiloea/videos/10220159696999011/

Al Punto. (2021). Video: Partido de Copa Libertadores es catalogado como "Vergüenza Nacional". Al Punto. Obtenido de https://alpunto.com.co/partido-de-copa-libertadores-escatalogado-como-verguenza-nacional/

Alabarces, P. (2014). Héroes, machos y patriotas. El fútbol entre la violencia y los medios. Buenos Aires: Aguilar.

Armagedón. (05 de 04 de 2020). Facebook. Recuperado el 06 de 06 de 2020, de https://m.facebook.com/armagedonsdaucas/photos/a.1553952868150648/25632369938888 92/

Arroyo, D. (2014). BARRISMO SOCIAL Y COLECTIVO BARRISTA COLOMBIANO: LOS ANTECEDENTES DEL DISEÑO DE UNA POLÍTICA PÚBLICA. Cali: Tesis (Pregrado en Profesional en Estudios Políticos y Resolución de conflictos)- Universidad del Valle. Obtenido de https://bibliotecadigital.univalle.edu.co/bitstream/handle/10893/7106/3489-

0430849. pdf;jsessionid=46FD4E6F27E29364BFF75ACB83420EB0?sequence $=1$ 
Dossiê | Hinchas organizados: ¿barras bravas o barristas sociales? Una mirada desde Colombia y Ecuador (RAMíREZ, Jacques; SALAZAR, Santiago)

Barras colombianas por la convivencia. (23 de 2019). https://www.facebook.com/Barras-colombianas-por-la-convivencia-484375178758951.

Recuperado el 02 de 02 de 2021, de https://www.facebook.com/Barras-colombianas-por-laconvivencia-484375178758951

Barras colombianas por la convivencia. (19 de 11 de 2019). www.facebook.com/Barrascolombianas-por-la-convivencia. Recuperado el 01 de 02 de 2020, de https://www.facebook.com/permalink.php?story_fbid $=654949335034867 \& i d=484375178758$ 951

Barras colombianas por la convivencia. (13 de 06 de 2021). https://www.facebook.com/Barras-colombianas-por-la-convivencia-484375178758951.

Recuperado el 15 de 06 de 2021, de https://www.facebook.com/permalink.php?story_fbid=1060473447815785\&id=48437517875 8951

Bolaños, D. (2007). No más barras bravas...barras populares. Revista Kinesis, 46, 1-14.

Bubu. (6 de 07 de 2020). Entrevista telefónica a "Bubu", referente de La Banda Tricolor. (S. Salazar, Entrevistador)

Came. (03 de 07 de 2021). Audio de WhatsApp, "Came" responde a nuestras preguntas. (S. Salazar, Entrevistador)

Clavijo, J. (2004). Estudio de barras de fútbol de Bogotá: Los Comandos Azules. Universitas Humanísticas, 43- 59.4 Obtenido de https://revistas.javeriana.edu.co/index.php/univhumanistica/article/view/9512

Colectivo Futbolero Colombiano. (16 de 01 de 2016). Colectivo Futbolero Colombiano CFC. Recuperado el 05 de 05 de 2020, de Página oficial de Facebook del Colectivo Futbolero Colombiano

CFC: https://www.facebook.com/CFCoficial2016/photos/pcb.962677320512158/962677023845521

Colectivo Futbolero Colombiano. (1 de 04 de 2016). Página oficial de Facebook del Colectivo Futbolero Colombiano CFC. Recuperado el 05 de 05 de 2020, de https://www.facebook.com/CFCoficial2016/photos/a.962236907222866/962236740556216/? type $=3$

Colectivo Futbolero Colombiano. (14 de 04 de 2016). Página oficial de Facebook del Colectivo Futbolero Colombiano CFC. Recuperado el 05 de 05 de 2020, de https://www.facebook.com/CFCoficial2016/photos/pcb.963321600447730/963321517114405

Dammert, M. (2007). Fútbol y violencias en el Ecuador: Espectáculo y análisis. Boletín Ciudad Segura, 20.2 Obtenido de https://repositorio.flacsoandes.edu.ec/bitstream/10469/2744/1/BFLACSO-CS21-04Dammert.pdf

Dammert, M. (2008). Fútbol y violencias en el Ecuador: Espectáculo y análisis. Ciudad segura 21, 4-10.

El Espectador. (19 de 04 de 2021). \$1.800 la docena: ¿dónde compra huevos el ministro Carrasquilla? El Espectador. Obtenido de https://www.elespectador.com/politica/1800-ladocena-donde-compra-huevos-el-ministro-carrasquilla-article/

El Niño Dios. (14 de 07 de 2021). Conversación casual por WhatsApp. (S. Salazar, Entrevistador)

El Niño Dios. (05 de 06 de 2021). Entrevista al "Niño Dios", conversación por teléfono. (S. Salazar, Entrevistador) 
Dossiê | Hinchas organizados: ¿barras bravas o barristas sociales? Una mirada desde Colombia y Ecuador (RAMÍREZ, Jacques; SALAZAR, Santiago)

El País. (02 de 02 de 2017). Asesinan a 'Toyota', testigo clave en infiltración de narcos en barra del América. El País. Obtenido de https://www.elpais.com.co/judicial/asesinan-a-toyotatestigo-clave-en-infiltracion-de-narcos-en-barra-del-america.html

El Tiempo. (04 de 06 de 2021). Así ha sido la participación de las barras bravas en el paro. El Tiempo. Obtenido de https://www.eltiempo.com/colombia/otras-ciudades/paro-nacionalparticipacion-de-las-barras-bravas-en-las-marchas-593192

Herrera, S. (15 de 06 de 2021). Monumento a la Resistencia de Cali: así es la obra conmemorativa del Paro Nacional creado por los manifestantes. Diario AS Colombia. Obtenido de https://colombia.as.com/colombia/2021/06/15/actualidad/1623778827_057371.html

Instructivo de control de ingreso de objetos a escenarios deportivos, 8168 (9 de 02 de 2017).

Linares, E. (2019). CON LA CASACA DEL BARRISMO SOCIAL. Bogotá: Tesis (Pregrado Licenciatura en Educación Básica con Énfasis en Ciencias Sociales)- Universidad Distrital Francisco José De Caldas. Obtenido de https://repository.udistrital.edu.co/bitstream/handle/11349/23569/LinaresCamposErika2019. pdf?sequence $=1 \&$ isAllowed $=y$

Londoño, Á., \& Pinilla, V. (2009). El Barrismo Social de Hinchas por Manizales. Una práctica política y ciudadana. Revista Austral de Ciencias Sociales, 73- 88. Obtenido de http://revistas.uach.cl/pdf/racs/n16/art05.pdf

Maffesoli, M. (2000). El tiempo de las tribus: el ocaso del individualismo en las sociedades posmodernas. Buenos Aires: Siglo XXI editores. Obtenido de https://books.google.es/books?hl=es\&lr=lang_es\&id=sBN9Dpqko0sC\&oi=fnd\&pg=PA6\&dq=mi chel+maffesoli\&ots=gVqD69mXIs\&sig=OzCw6SkGMUKyziTWAAOaSdnMIOs\#v=onepage \&q=mic hel\%20maffesoli\&f=false

Marea Roja. (02 de 10 de 2019). Facebook. Recuperado el 06 de 06 de 2020, de https://www.facebook.com/marearojaec/posts/10156362302787382

Marea Roja. (03 de 08 de 2020). Facebook. Recuperado el 06 de 08 de 2020, de https://www.facebook.com/watch/?v=749582712499669

Marea Roja. (05 de 10 de 2020). Facebook. Recuperado el 10 de 10 de 2020, de https://www.youtube.com/watch?v=uxjh5uby96E\&fbclid=IwAR12pxVRNkwLq1Waf9ttkNuwuo Hs23fuAg3F94r8oM8XxFnLFboShJONKxc

Mesa de barrismo popular y social Pasto. (11 de 05 de 2021). Facebook Oficial de La Banda Tricolor. Recuperado el 07 de 06 de 2021, de Facebook Oficial de La Banda Tricolor: https://www.facebook.com/labandatricolorpasto1949/photos/pcb.2880617488817497/28806 17448817501

Ministerio del Interior. (2014- 2024). Plan Decenal de Seguridad, Comodidad y Convivencia en el Fútbol. Bogotá: Gente Nueva. Obtenido de https://adsdatabase.ohchr.org/IssueLibrary/COLOMBIA_Plan\%20Decenal\%20de\%20Seguridad \%20Comodiad\%20y\%20Convivencia\%20en\%20el\%20Futbol\%202014-2024.pdf

Muerte Blanca. (18 de 04 de 2016). Facebook. Recuperado el 06 de 06 de 2020, de https://www.facebook.com/BlancaNavidadMB/posts/1071024542945781

Muerte Blanca. (06 de 11 de 2016). Facebook. Recuperado el 07 de 06 de 2020, de https://www.facebook.com/BlancaNavidadMB/

Muerte Blanca. (12 de 04 de 2020). Facebook. Recuperado el 06 de 06 de 2020, de https://www.facebook.com/reydeacopas/photos/a.851588358361482/1440729389447373/ 
Dossiê | Hinchas organizados: ¿barras bravas o barristas sociales? Una mirada desde Colombia y Ecuador (RAMÍREZ, Jacques; SALAZAR, Santiago)

Primera escuela urbana de Barrismo Popular (2020). Primera clase de la escuela urbana de barrismo popular (Pasto). Pasto, Nariño, Colombia.

Pulzo. (2017). Audios de venganza y hasta secuestro tras robo de trapos de hinchas del Cali al DIM. Pulzo.com. Obtenido de https://www.pulzo.com/deportes/robo-trapos-hinchascali-dim-PP207311

Ramírez, J. (2017). Torcidas organizadas, territórios e violencia no futebol equatoriano. En B. Borges, B. de Hollanda, \& O. Rodríguez Org., Torcidas organizadas na América Latina. Estudios comtemporaneos (págs. 154- 173). Río de Janeiro: Viveiros de Castro Editora.

Restrepo, J. M. (2018). Plan Decenal de Seguridad, Comodidad y Convivencia en el Fútbol: entre la vigilancia y la voluntad política, un análisis comparado sobre la política del fútbol colombiano los casos de Cali y Medellín". Quito: Tesis (Maestría de Investigación en Estudios Urbanos)- FLACSO Ecuador.

Saín, M., \& Rodríguez, N. (2014). Los actores y la seguridad en el fútbol. Una lectura desde Argentina. En F. Carrión, \& M. Rodríguez coordinadores, Luchas urbanas alrededor del fútbol (págs. 213- 239). Quito: 5ta Avenida Editores.

Salazar, D. (2019). Barrismo social y política pública para la convivencia en el fútbol: Experiencias transformadoras en las ciudades de Bogotá y San Juan de Pasto. Trans-pasando fronteras, 160- 202. Obtenido de https://www.icesi.edu.co/revistas/index.php/transpasando_fronteras/article/view/3399/3633

Salazar, S. (2021). Entre hinchas y barras: Un análisis sociopolítico aplicad a la capital del Ecuador (2002- 2020). Quito: Tesis (Maestría de Investigación en Sociología Política)- FLACSO Ecuador.

Triviñas. (04 de 07 de 2020). Conversación por teléfono con "Triviñas", viejo referente de Los del Sur- Popayán. (S. Salazar, Entrevistador)

Velásquez, M. (05 de 06 de 2021). ¿Qué es la primera línea de las protestas en Colombia y qué es lo que piden? CNN. Obtenido de https://cnnespanol.cnn.com/2021/07/05/que-es-laprimera-linea-de-las-protestas-en-colombia-y-que-es-lo-que-piden/

Villanueva, A. (2014). Entre la zanahoria, el garrote, la estigmatización y el abandono de las hinchadas en Colombia. Esporte $e$ Sociedade. Obtenido de https://periodicos.uff.br/esportesociedade/article/view/49233/28632

Viver, I. (2014). "Socialización, género y violencia en las culturas adolescentes: el caso de la barra brava "Mafia Azul Grana". Tesis de Maestría en Políticas Sociales de la infancia y adolescencia. Quito: Universidad Salesiana.

\section{Portales}

Armagedón. (05 de 04 de 2020). Facebook. Recuperado el 06 de 06 de 2020, de https://m.facebook.com/armagedonsdaucas/photos/a.1553952868150648/25632369938888 92/

Barras colombianas por la convivencia. (23 de 2019). https://www.facebook.com/Barras-colombianas-por-la-convivencia-484375178758951.

Recuperado el 02 de 02 de 2021, de https://www.facebook.com/Barras-colombianas-por-laconvivencia-484375178758951

Barras colombianas por la convivencia. (19 de 11 de 2019). www.facebook.com/Barrascolombianas-por-la-convivencia. Recuperado el 01 de 02 de 2020, de 
Dossiê | Hinchas organizados: ¿barras bravas o barristas sociales? Una mirada desde Colombia y Ecuador (RAMíREZ, Jacques; SALAZAR, Santiago)

https://www.facebook.com/permalink.php?story_fbid=654949335034867\&id $=484375178758$ 951

Barras colombianas por la convivencia. (13 de 06 de 2021). https://www.facebook.com/Barras-colombianas-por-la-convivencia-484375178758951.

Recuperado el 15 de 06 de 2021, de https://www.facebook.com/permalink.php?story_fbid=1060473447815785\&id=48437517875 8951

Colectivo Futbolero Colombiano. (16 de 01 de 2016). Colectivo Futbolero Colombiano CFC. Recuperado el 05 de 05 de 2020, de Página oficial de Facebook del Colectivo Futbolero Colombiano

CFC: https://www.facebook.com/CFCoficial2016/photos/pcb.962677320512158/962677023845521

Colectivo Futbolero Colombiano. (1 de 04 de 2016). Página oficial de Facebook del Colectivo Futbolero Colombiano CFC. Recuperado el 05 de 05 de 2020, de https://www.facebook.com/CFCoficial2016/photos/a.962236907222866/962236740556216/? type $=3$

Colectivo Futbolero Colombiano. (14 de 04 de 2016). Página oficial de Facebook del Colectivo Futbolero Colombiano CFC. Recuperado el 05 de 05 de 2020, de https://www.facebook.com/CFCoficial2016/photos/pcb.963321600447730/963321517114405

Marea Roja. (03 de 08 de 2020). Facebook. Recuperado el 06 de 08 de 2020, de https://www.facebook.com/watch/?v=749582712499669

Mesa de barrismo popular y social Pasto. (11 de 05 de 2021). Facebook Oficial de La Banda Tricolor. Recuperado el 07 de 06 de 2021, de Facebook Oficial de La Banda Tricolor: https://www.facebook.com/labandatricolorpasto1949/photos/pcb.2880617488817497/28806 17448817501

Muerte Blanca. (18 de 04 de 2016). Facebook. Recuperado el 06 de 06 de 2020, de https://www.facebook.com/BlancaNavidadMB/posts/1071024542945781

Muerte Blanca. (12 de 04 de 2020). Facebook. Recuperado el 06 de 06 de 2020, de https://www.facebook.com/reydeacopas/photos/a.851588358361482/1440729389447373/

Pulzo. (2017). Audios de venganza y hasta secuestro tras robo de trapos de hinchas del Cali al DIM. Pulzo.com. Obtenido de https://www.pulzo.com/deportes/robo-trapos-hinchascali-dim-PP207311

\section{Prensa}

El País. (2017). Asesinan a 'Toyota', testigo clave en infiltración de narcos en barra del América. El País, 02.202017.

Obtenido de https://www.elpais.com.co/judicial/asesinan-a-toyota-testigo-clave-eninfiltracion-de-narcos-en-barra-del-america.html

El Tiempo. (2021). Así ha sido la participación de las barras bravas en el paro. El Tiempo, 04.06.2017

Obtenido de https://www.eltiempo.com/colombia/otras-ciudades/paro-nacionalparticipacion-de-las-barras-bravas-en-las-marchas-593192 